\title{
APPLICATIONS OF FAN'S MATCHING THEOREM IN MKKM SPACES
}

\section{Madjid Eshaghi Gordji, Mohsen Rostamian Delavar and Mehdi Roohi}

Abstract. Using some concepts in MKKM space, we prove the generalized forms of open and closed versions of Fan's matching theorem. The $S$-weakly KKM multimap is applied to obtain a type of KKM theorem. As an application, a Fan type minimax theorem is proved. Moreover, a minimax inequality is given in these new settings.

Mathematics subject classification (2010): 26A51, 26B25, 54H25, 55M20, 47H10, 54A05.

Keywords and phrases: abstract convex minimal space, MKKM space, KKM theorem, $S$-weakly KKM map, matching theorem, minimax inequalities.

\section{REFERENCES}

[1] M. Alimohammady AND M. Roohi, Extreme points in minimal spaces, Chaos, Solitons \& Fractals 39, 3 (2009), 1480-1485.

[2] M. Alimohammady, M. Roohi, Linear minimal space, Chaos, Solitons \& Fractals. 33, 4 (2007), $1348-1354$.

[3] M. Alimohammady, M. Roohi And M. R. Delavar, Knaster-Kuratowski-Mazurkiewicz theorem in minimal generalized convex spaces, Nonlinear Funct. Anal. Appl. 13, 3 (2008), 483-492.

[4] M. Alimohammady, M. Roohi And M. R. Delavar, Transfer closed and transfer open multimaps in minimal spaces, Chaos, Solitons \& Fractals 40, 3 (2009), 1162-1168.

[5] M. BalaJ, Two minimax inequality in G-convex spaces, Appl. Math. Lett. 19 (2006), 235-239.

[6] M. BALAJ, Weakly G-KKM mappings, G-KKM property, and minimax inequalities, J. Math. Anal. Appl. 294, 1 (2004), 237-245.

[7] H. Ben-El-Mechaiekh, S. Chebbi, M. Florenzano and J. V. Llinares, Abstract convexity and fixed points, J. Math. Anal. Appl. 222 (1998), 138-150.

[8] T. H. Chang, Y. Y. HuAng, J. C. Jeng AND K. W. KuO, On S-KKM property and related topics, J. Math. Anal. Appl. 229 (1999), 212-227.

[9] M. S. R. CHOWDHURY AND K. K. TAN, Generalization of Ky Fan's minimax inequality with applications to generalized variational inequalities for pseudomonotone operators and fixed-point theorems, J. Math. Anal. Appl. 204 (1996), 910-929.

[10] K. FAN, A minimax inequality and applications, in: O.Sisha (Ed.), Inequalities, vol. III, Academic Press, San Diego, 1972, 103-113.

[11] C. W. HA, Minimax and fixed point theorem, Math. Ann. 248 (1980), 73-77.

[12] C. D. Horvath, Contractibility and generalized convexity, J. Math. Anal. Appl. 156 (1991), 341-357.

[13] J. KIM, KKM theorems and minimax inequalities in G-convex spaces, Nonlinear Anal. Forum 6 (2001), 135-142.

[14] M. LASSONDE, On the use of KKM multifunctions in fixed point theory and related topics, J. Math. Anal. Appl. 97 (1983), 151-201.

[15] L. J. LiN, Applications of a fixed point theorem in G-convex spaces, Nonlinear Anal. 46 (2001), 601-608.

[16] F. C. LIU, On a form of KKM principle and supinfsup inequalities of Von Neumann and of Ky Fan type, J. Math. Anal. Appl. 155, 2 (1991), 420-436.

[17] H. MAKI, On generalizing semi-open sets and preopen sets, Meeting on Topological Spaces Theory and its Application, Augoust 1996, 13-18.

[18] H. Maki, J. Umehara And T. NoIRI, Every topological space is pre $T_{\frac{1}{2}}$, Mem. Fac. Sci. Kochi Univ. Ser A. Math. 17 (1996), 33-42. 
[19] S. PARK, Applications of the KKM principle on abstract convex minimal spaces, Nonlinear Funct. Anal. Appl. 13, 2 (2008), 179-191.

[20] S. PARK, Remarks on weakly KKM maps in abstract convex spaces, Int. J. Math. Math. Sci. 2008, 1 (2008), Article ID 423596, 10 pages, doi:10.1155/2008/423596.

[21] S. PARK, The KKM principle in abstract convex spaces: Equivalent formulations and applications, Nonlinear Anal. 73 (2010), 1028-1042.

[22] S. PARK, Various subclasses of abstract convex spaces for the KKM theory, Proc. Nat. Math. Sci. 2 (2007), 35-47.

[23] S. PARK, On generalizations of the KKM principle on abstract convex spaces, Nonlinear Anal. Forum 11, 1 (2006), 67-77.

[24] S. PARK AND H. Kim, Admissible classes of multifunctions on generalized convex spaces, Proc. Coll. Nature. Sci. SNU. 18 (1993), 1-21.

[25] V. Popa And T. NoIRI, On M-continuous functions, Anal. Univ. "Dunarea Jos"-Galati, Ser. Mat. Fiz. Mec. Teor. Fasc. II 18, 23 (2000), 31-41.

[26] K. K. TAN, G-KKM theorem, minimax inequalities and saddle points, Nonlinear Anal. 32 (1997), 4151-4160.

[27] G. S. TANG, Q. B. ZHANG, AND C. Z. CHENG, W-G-F-KKM mapping, intersection theorems and minimax inequalities in FC-space, J. Math. Anal. Appl. 334, 2 (2007), 1481-1491. 